\title{
Investment-Specific and Multifactor Productivity in Multi-Sector Open Economies: Data and Analysis
}

\author{
Luca Guerrieri, Dale W. Henderson, and Jinill Kim* \\ Federal Reserve Board
}

January 28, 2005

\footnotetext{
*The views in this paper are solely the responsibility of the authors and should not be interpreted as reflecting the views of the Board of Governors of the Federal Reserve System or any other person associated with the Federal Reserve System. Helpful comments were received from participants in the conference entitled 'Dynamic Macroeconomic Theory' held at the University of Copenhagen on June 11-13, 2004 and in seminars at the International Finance Division of the Federal Reserve Board and Georgetown University. We had useful discussions with Susantu Basu, David Bowman, Andrea DeMichelis, Charles Engel, Christopher Erceg, Christopher Gust, Jon Faust, Jaime Marquez, John Rogers, Daniel Sichel, and Jonathan Wright. Remaining errors are ours.
} 


\begin{abstract}
In the last half of the 1990s, labor productivity growth rose in the U.S. and fell almost everywhere in Europe. We document changes in both capital deepening and multifactor productivity $(M F P)$ growth in both the information and communication technology $(I C T)$ and non- $I C T$ sectors. We view $M F P$ growth in the $I C T$ sector as investment-specific productivity $(I S P)$ growth. We perform simulations suggested by the data using a two-country $D G E$ model with traded and nontraded goods. For $I S P$, we consider level increases and persistent growth rate increases that are symmetric across countries and allow for costs of adjusting capital-labor ratios that are higher in one country because of structural differences. ISP increases generate investment booms unless adjustment costs are too high. For $M F P$, we consider persistent growth rate shocks that are asymmetric. When such $M F P$ shocks affect only traded goods (as often assumed), movements in 'international' variables are qualitatively similar to those in the data. However, when they also affect nontraded goods (as suggested by the data), movements in some of the variables are not. To obtain plausible results for the growth rate shocks, it is necessary to assume slow recognition.
\end{abstract}

JEL Classifications: D83, F43, O41

Keywords: Technology Shocks, DGE models, Learning 


\section{Introduction}

Changes in labor productivity growth in the U.S. and Europe are among the major economic events of the last fifteen years. There now seems to be general agreement that in the last half of the 1990s, labor productivity growth rose in the U.S. and fell almost everywhere in Europe. In the first half of the 1990s, U.S. growth was significantly below that in European countries, but in the second half the situation was reversed in almost every case. Recently, several analysts have provided breakdowns of changes in labor productivity growth by country, by component, and by sector. ${ }^{1}$

Some generalizations are suggested by the data. In both the U.S. and Europe there were increases in multifactor productivity $(M F P)$ growth in the information and communication technology $(I C T)$ sector. It came as a surprise to us that these increases were the same or even greater in Europe. As a consequence, there were sharp reductions in the relative prices of $I C T$ goods. $^{2}$ At least partly for this reason, capital deepening through investment in information and communication technology $(I C T)$ goods increased in both the U.S. and Europe, but the increase was about twice as great in the U.S. We treat $M F P$ growth in the $I C T$ sector as investment-specific productivity $(I S P)$ growth, a convention adopted by several others. ${ }^{3}$

$M F P$ growth in the non- $I C T$-producing sector rose by a significant amount in the U.S. and by comparable amounts in some European countries but fell by more than double these amounts in other European countries. Capital deepening through investment in non- $I C T$ goods increased markedly in the U.S. but decreased in Europe. Increases in both labor productivity growth and $M F P$ growth have been higher in the U.S. in important sectors that produce mostly nontraded goods.

The changes in relative productivity growth rates in the last half of the 1990s were accompanied by some dramatic changes in other variables. In the U.S., there was an investment boom, a deterioration in the trade account, a temporary improvement in the terms of trade, and a significant real appreciation of the dollar.

In an attempt to provide perspective on the data, we perform simulations using a $D G E$ model with two countries (Home and Foreign). ${ }^{4}$ Each country produces a traded good and a nontraded good, and the two traded goods are imperfect substitutes for each other. ${ }^{5}$ In each country, consumption and investment goods are aggregates

\footnotetext{
${ }^{1}$ Most of our data come from three sources: the Groningen Growth and Development Center, Dale Jorgenson and his associates, and the Organization for Economic Co-operation and Development.

${ }^{2}$ To be more precise, what happened in the last half of the 1990s was an increase in the rate of decline of the relative price of investment goods.

${ }^{3}$ See, for example, Greenwood, Hercowitz, and Krusell (1997).

${ }^{4}$ Pioneering contributions to the analysis of productivity shocks in open-economy DGE models include Backus, Kehoe, and Kydland (1994b), Backus, Kehoe, and Kydland (1994a), Stockman and Tesar (1995), Baxter and Crucini (1995), and Kollmann (1998). Recent contributions include Erceg, Guerrieri, and Gust (2002), Laxton and Pesenti (2003), and Hunt and Rebucci (2003). Closed economy contributions include Edge, Laubach, and Williams (2003, 2004).

${ }^{5}$ Nontraded goods are clearly a large fraction of output in the U.S. (and Europe). The (increasingly unsatisfactory) convention of indentifying goods as traded and services as nontraded leads to the conclusion that $75 \%$ or so of output is nontraded. Taking account of the familiar argument that some services are traded, we assume that nontraded goods constitute $63 \%$ of consumption and $52 \%$ investment. These figures are in the middle of the (admittedly large) range of assumptions in the
} 
assembled using the two traded goods and the local nontraded good. The baskets of traded goods used in both consumption and investment are biased toward the locallyproduced good, but the 'local bias' in consumption is greater. The model nests most two-country $D G E$ models used over the past fifteen years to analyze productivity changes.

Our reading of the disparate productivity-growth experiences of the U.S. and Europe has determined our choice of simulation experiments. We focus primarily on two persistent productivity growth shocks. The first is a symmetric ISP growth shock. This shock has different effects on the two countries because one of them has less structural rigidity reflected in lower costs of adjusting capital-labor $(K-L)$ ratios. The second is an MFP growth shock that is (perfectly) asymmetric across countries. Departing from much previous analysis, we emphasize the case in which the shock affects both the traded and nontraded sectors. To take account of slow adjustment of consumption and slow recognition of persistent growth shocks, we incorporate habit in consumption and learning about shocks. To fix ideas, we consider symmetric ISP level shocks before discussing the two growth shocks.

We calibrate the symmetric ISP growth shock so that it causes an increase in the rate of decline of the relative price of investment that closely matches the one in U.S. data. In the country with low $K-L$ adjustment costs, the investment incentive of the shock is large relative to the wealth effect. As a result, there is an investment boom, an actual reduction in consumption for several periods, and a modest trade deficit. In contrast, in the country with high $K-L$ adjustment costs, the wealth effect dominates: investment increases very little, but consumption rises significantly. The movements in the TOT and the $R E R$ are qualitatively quite different from those in the data.

We calibrate the asymmetric $M F P$ growth shock so that for the country receiving the increase, the initial rise in labor productivity growth is the same as for the symmetric $I S P$ shock. With MFP shocks, the wealth effect is large relative to the investment incentive. For positive shocks, both consumption and investment rise, and there is a sizeable trade deficit. The large wealth effect combined with local-good bias keeps the TOT from deteriorating for a while since demand for the local traded good increases by as much as supply.

In succeeding sections, we present data relevant for analyzing productivity shocks in the U.S. and Europe, our model, our simulations, and our conclusions.

\section{Data}

\subsection{Accounting for Changes in Labor Productivity Growth}

Much progress has been made in accounting for changes in labor productivity growth in the U.S. and Europe during the 1990s. ${ }^{6}$ It is no easy task to separate out the contri-

\footnotetext{
literature.

${ }^{6}$ In this paper we do not attempt to explain why labor productivity growth was higher in Europe for many years before 1995 or to compare the levels of labor productivity in the U.S. and Europe.
} 
butions of capital deepening and multi-factor productivity growth for the economy as a whole and for individual sectors. ${ }^{7}$ Data revisions and improvements in methodology continue to have significant effects on conclusions.

Here we focus primarily on data from three sources: the Groningen Growth and Development Center (GGDC), Dale Jorgenson and his associates, and the Organization for Economic Co-operation and Development (OECD) STandard ANalysis data base. $^{8}$ Data from all three sources have at least three desirable features: they (1) are reported on a standardized basis across several countries, (2) include estimates of hours instead of only the number of employees for all countries, and (3) include estimates of real investment that are quality adjusted using the same methodology.

Table 1 contains a comparison of GGDC and Jorgenson data for the U.S., France, Germany, and the U.K. ${ }^{9}$ In addition, for the GGDC there are data for the Netherlands and an aggregate called the 'EU-4' (France, Germany, the U.K., and the Netherlands). For Jorgenson there are data for Italy but there is no aggregate of European countries. In our comparisons we use average annual growth rates for the periods 1990-1995 and 1996-2001. We focus our attention on changes in average growth rates between the two periods in the U.S. and European countries. Unless stated otherwise, growth rate differences are presented in percentage point (pp) form.

Changes in U.S. growth rates are essentially the same in the data from the GGDC and Jorgenson, and we will treat them as if they were the same in what follows. ${ }^{10}$ Most of the major qualitative features that we choose to emphasize can be illustrated by comparisons between the U.S. and the EU-4 aggregate in the GGDC data. ${ }^{11}$ In the last half of the 1990s, labor productivity growth rose in the U.S. and fell in Europe resulting in a difference between changes in growth rates of $1.5 \mathrm{pp}$. In the first half of the 1990s, U.S. labor productivity growth was significantly below that in the EU-4, but in the second half it was slightly above.

Using the same data, the changes in labor productivity can be broken down into changes in components. Overall capital deepening increased in the U.S.: there were increases for both $I C T$ capital $(0.4 \mathrm{pp})$ and non- $I C T$ capital $(0.2 \mathrm{pp})$. In contrast, overall capital deepening fell in the EU-4 because the increase in ICT capital deepening (0.2 pp) was only half as much as in the U.S. and was more than offset by the decrease in non-ICT capital deepening (-0.6 pp). The contribution of $M F P$ growth increased in both the U.S. and the EU-4 but the U.S. increase was more than twice as high (0.7 pp versus $0.3 \mathrm{pp})$.

The Jorgenson data include a breakdown of the contributions of $M F P$ growth into those from $I C T$-producing sectors and those from all other sectors. These data

\footnotetext{
${ }^{7}$ Some analysts also separate out a contribution of changes in labor quality, but in this paper we abstract from such changes.

${ }^{8}$ Two GGDC sources are GGDC (2004) and Inklar, O'Mahony, Robinson, and Timmer (2003). The work of Jorgenson and his associates is summarized in Jorgenson (2004). For the OECD STAN data base source, see Organization for Economic Co-operation and Development (2004).

${ }^{9}$ The GGDC data come from GGDC (2004) and the Jorgenson data come from Jorgenson (2004).

${ }^{10}$ The possible exceptions to this statement are the growth rates for labor quality which are not considered in this paper.

${ }^{11}$ In the GGDC data, France is the only country where the qualitative pattern is different from that in the EU-4 aggregate.
} 
confirm earlier findings that there has been a significant increase in the contribution of $M F P$ growth in $I C T$ producing sector in the U.S. (0.3 pp). ${ }^{12}$ However, it came as a surprise to us that they also imply that the contribution of this sector has been just as high in the European countries. In the non- $I C T$ sectors, $M F P$ growth increased by $0.4 \mathrm{pp}$ in the U.S. and by slightly more in France and the U.K. but fell by $1.2 \mathrm{pp}$ in Italy and by even more in Germany.

There has been much interest in the sectoral breakdown of the changes in labor productivity growth. Using OECD data on value added by sector in the U.S. (a rearrangement of BEA data) we constructed a sectoral breakdown of labor productivity growth for the U.S. which is shown in the leftmost three columns of Table $2 .{ }^{13}$ It appears that most of the pickup in aggregate growth was accounted for by three sectors: Manufacturing (0.2 pp); Wholesale and Retail Trade; Restaurants and Hotels (0.4 pp); and Finance, Insurance, Real Estate, and Business Services (0.2 pp).

Conceptually, sectoral contributions to changes in aggregate labor productivity growth can be broken down into changes in capital deepening and changes in $M F P$ growth. As it turns out, it is difficult to reach definitive conclusions about the relative importance of these contributions. There is evidence that sectoral changes in $I C T$ capital deepening have been important. As an example, the data in Table 2 provide some support for the view that the sectors that have made the largest sectoral contributions are the ones with the biggest increases in investment in $I C T$ goods. Sectoral data for the ratio of nominal gross investment in $I C T$ goods to nominal value added are shown in the rightmost three columns of Table 2. The increases in this ratio for Wholesale and Retail Trade as well as Finance, Insurance, Real Estate \& Business Sector Services are significantly larger than for all of the other sectors (except Transportation, Storage, and Communication). These are two of the three sectors that made the largest contributions. However, even though Manufacturing is the third, the increase in its ratio is on the low end. Furthermore, by far the largest increase in the ratio occurred in the Transportation, Storage, and Communication sector, where there was a negative contribution.

There is also evidence that sectoral changes in $M F P$ growth have been important. Inklar, O'Mahony, Robinson, and Timmer (2003) show that some of the sectors that have made the largest contributions to the increase in the difference between aggregate U.S. and EU-4 labor productivity growth are sectors in which increases in the difference between $M F P$ growth rates have also been high. ${ }^{14}$ According to their data, for some of these sectors the increases in $M F P$ growth were considerably more important than the increases in $I C T$ capital deepening. ${ }^{15}$ Three sectors which exhibit both of these phenomena are (1) Electrical and Electronic Equipment; Instruments, (2) Repairs and Wholesale Trade, and (3) Retail Trade.

We believe that the data clearly suggest at least three generalizations regarding

\footnotetext{
${ }^{12}$ See, for example, Oliner and Sichel (2000).

${ }^{13}$ The contributions in Table 2 are calculated using the standard methodology summarized in equation A.43 on p. 145 of Schreyer (2001).

${ }^{14}$ See their Figure III.3.c. The analysis in Fernald and Ramnath (2004) also supports this conclusion.

${ }^{15}$ See their Appendix Tables III.C.1 through III.C.6.
} 
the breakdown of the increase in the difference between U.S. and European labor productivity growth rates. First, although MFP growth in the ICT sector was roughly the same in the U.S. and Europe, there have been important increases in differences between $I C T$ capital deepening in both $I C T$-producing and non-ICTproducing sectors. Second, $M F P$ growth in the non- $I C T$-producing sectors increased in the U.S. but fell on balance in Europe. Third, in contrast to what some might have expected, there have been significant increases in differentials in MFP growth rates nontraded goods as well as for traded goods. We have taken these generalizations into account in constructing the model that we use to shed light on recent experience.

\subsection{More on the U.S. Economy in the 1990s}

Some additional data for the U.S. economy relevant for analyzing the effects of productivity shocks are shown in Figure 1. In discussing figures, we use the convention that, for example, 'panel 4 of Figure 1' is referred to simply as 'F1.4'.

In the second half of the 1990s, the decline in prices of investment goods became more rapid. In particular, the rate of decline in the price of aggregate investment relative to $G D P$ (F1.1) increased by $0.69 \mathrm{pp}$. A greater increase for consumer durables and a smaller increase for private investment (by businesses) more than offset the small decline for government investment. For the subcategory of investment in equipment and software, the increase was $1.28 \mathrm{pp}$.

At least partly in response to this more rapid rate of price decline, there was an investment boom. The share of investment in GDP (broken line F1.4) rose throughout this period from about 0.19 to about 0.22 . In contrast, the saving rate, the solid line, climbed by 2 pp between 1995 and 1998 but fell back to slightly below its 1994 level by the end of 2000. Since the fraction of GDP devoted to government spending was fairly constant in the late 1990s, the continued increase in investment accompanied by the reduction in savings implied a deterioration in the overall U.S. trade balance (F1.5).

The increase in the nominal investment share does not fully capture the magnitude of the investment boom because of the decline in prices of investment goods. To better capture the relative magnitude of the changes in quality-adjusted real investment, we plot the difference between the growth rates of chain-weighted real investment and chain-weighted real GDP (F1.2). The difference between these two growth rates got at least as high in the last half of the 1990s as in earlier booms and remained high much longer. Furthermore, the drop in the difference in the recession of the early 2000s was significantly less than in earlier recessions.

What is not shown in Figure 1 is that an overwhelming portion of growth in investment can be attributed to outlays for ICT investment (information-processing equipment and computer software); nominal outlays on these item were $9 \%$ of total nominal investment in 1990 and $22 \%$ in 1999. Real outlays grew faster because computer prices fell. The increase in $I C T$ investment growth accounts for $60 \%$ of the increase in all investment. ${ }^{16}$

\footnotetext{
${ }^{16}$ See, for example, Bosworth and Triplett (2000).
} 
There was an abrupt increase in U.S. labor productivity growth (F1.3) in the second half of the 1990s. ${ }^{17}$

The overall U.S. trade balance as a ratio of GDP (F1.5, dotted line) deteriorated rapidly in the last half of the 1990s. We are especially interested in a comparison of the U.S. with Europe. The U.S. bilateral trade balance with the European Union (solid line) worsened slightly. After improving for a while, the overall trade balance for Europe (dashed line) fell below its initial level.

The U.S. terms of trade with the rest of the world (F1.6, dotted line) improved by as much as $5 \%$ before giving back much of its gain by the end of the decade. ${ }^{18}$ The dollar appreciated dramatically in real terms against the 'rest of the world' (dashed line) and even more dramatically against the Euro (solid line).

It apparently took some time for government and private analysts to become convinced that the increase in productivity growth was going to be persistent. Both the Congressional Budget Office and the consensus of Blue Chip forecasters produce five-year-ahead forecasts of real GDP growth. As reported by Erceg, Guerrieri, and Gust (2002), these forecasts were virtually unchanged until the late 1990s and then increased gradually.

\section{Model}

In our analysis of the effects of different productivity shocks, we use a $D G E$ model with two countries designated Home and Foreign which are mirror images of one another. We describe the behavior of the representative Home agent.

\subsection{Tastes}

In period $t$, the agent maximizes the intertemporal utility function

$$
\sum_{s=t}^{\infty} \beta^{s-t} \frac{V_{s}^{1-\gamma}-1}{1-\gamma}
$$

Period utility is a constant elasticity function of $V_{s}$ which, in turn, depends on the current consumption of the agent $\left(C_{s}\right)$, lagged total consumption $\left(\mathcal{C}_{s-1}\right)$, and leisure which is given by one minus labor $\left(L_{s}\right)$ :

$$
V_{s}=V\left(C_{s}, \mathcal{C}_{s-1}, L_{s}\right)=\left(\frac{C_{s}-\eta \mathcal{C}_{s-1}}{1-\eta}\right) \exp \left\{\chi_{0}\left[\frac{\left(1-L_{s}\right)^{1-\chi}-1}{1-\chi}\right]\right\} .
$$

That is, there is external habit in consumption. The agent also chooses holdings of a single bond $(B)$ denominated in the Home traded good (the numeraire good for the model) and traded internationally.

\footnotetext{
${ }^{17}$ The quarterly data shown come from the productivity release of the Bureau of Labor Statistics. It differs from the data presented in Table 1 in that it excludes the government and farm sectors.

${ }^{18}$ The US/ROW terms of trade is the ratio of the U.S. import deflator to the U.S. export deflator. We have not calculated a US/EURO terms of trade because there are no bilateral data for some countries in the Euro Area. The U.S./ROW real exchange rate is the ratio of the U.S. CPI to the trade-weighted sum of exchange-rate-adjusted CPIs for 25 major trading partners of the U.S.
} 


\subsection{Technology}

Home technology comprises six sectors. First, there are two sectors in which traded $(T)$ goods and nontraded $(N)$ goods are produced using identical Cobb-Douglas production functions scaled by adjustment costs:

$$
Y_{i s}=K_{i s}^{\alpha} L_{i s}^{1-\alpha} X_{i s}^{1-\alpha}\left[1-\frac{\psi_{K L}}{2}\left(\frac{K_{i s}}{L_{i s}} / \frac{K_{i s-1}}{L_{i s-1}}\right)^{2}\right]=F\left(\underline{K}_{i s}, \underline{L}_{i s}\right) X_{i s}^{1-\alpha}
$$

where $\underline{K}_{i s}$ and $\underline{L}_{i s}$ are vectors containing current and lagged values and $i=T, N$. For sector $i$, output $\left(Y_{i s}\right)$ is produced using sector-specific capital $\left(K_{i s}\right)$ and labor $\left(L_{i s}\right)$. The $T$ and $N$ sectors use all the labor that is supplied:

$$
L_{s}=L_{T s}+L_{N s}
$$

There are $M F P$ shocks $\left(X_{i s}\right)$ that may differ between the two sectors. For sector $i$, there are quadratic adjustment costs (governed by $\psi_{K L}$ ) associated with changing capital-labor ratios. Examples of such adjustment costs are training costs and costs of satisfying regulations.

Next, there are two sectors in which capital stocks are accumulated. In each of these sectors, yesterday's sector-specific capital stock $\left(K_{i s-1}\right)$ and some of yesterday's investment good $\left(J_{i s-1}\right)$ are used to generate today's sector-specific capital stock :

$$
K_{i s}=\left[\delta\left(\frac{J_{i s-1}}{\delta}\right)^{1-\phi}+(1-\delta)\left(K_{i s-1}\right)^{1-\phi}\right]^{\frac{1}{1-\phi}}, \quad i=T, N
$$

where $\phi$ governs the costs of adjusting capital stocks.

Finally, there are two sectors in which goods are assembled into a consumption good $\left(C_{s}\right)$ and an investment good $\left(J_{s}\right) . C_{s}$ is a constant elasticity of substitution (CES) function of consumption inputs of traded goods $\left(C_{T s}\right)$ and of the local nontraded good $\left(C_{N s}\right)$ :

$$
C_{s}=\left[\left(1-\nu_{C}\right)\left(\frac{C_{T s}}{1-\nu}\right)^{1-\theta_{C N}}+\nu_{C}\left(\frac{C_{N s}}{\nu}\right)^{1-\theta_{C N}}\right]^{\frac{1}{1-\theta_{C N}}}
$$

and $J_{s}$ is a CES function of 'quality-adjusted' investment inputs of traded goods $\left(\mathcal{I}_{T s}\right)$ and of the local nontraded good $\left(I_{N s}\right)$ :

$$
J_{s}=\left[\left(1-\nu_{I}\right)\left(\frac{\mathcal{I}_{T s}}{1-\nu}\right)^{1-\theta_{I N}}+\nu_{I}\left(\frac{I_{N s}}{\nu}\right)^{1-\theta_{I N}}\right]^{\frac{1}{1-\theta_{I N}}}
$$

where $\mathcal{I}_{T s}$ is the 'quality-adjusted' input of traded goods defined below. In assembly sector $i$, where $i=I, C$, the parameters $\nu_{i}$ and $1 / \theta_{i N}$ are, respectively, the weight given to nontraded goods in production and the elasticity of substitution between traded and nontraded goods. 
In turn, the consumption input of traded goods is a CES function of consumption inputs of Home traded goods $\left(C_{H s}\right)$ and of Foreign traded goods $\left(C_{F s}\right)$ :

$$
C_{T s}=\left[\ell_{C}\left(\frac{C_{H s}}{\ell_{C}}\right)^{1-\theta_{C T}}+\left(1-\ell_{C}\right)\left(\frac{C_{F s}}{1-\ell_{C}}\right)^{1-\theta_{C T}}\right]^{\frac{1}{1-\theta_{C T}}}, \quad \ell_{C}=n+\kappa_{C} .
$$

By analogy, the investment input of quality-adjusted traded goods is a CES function of quality-adjusted inputs of Home traded goods $\left(\mathcal{I}_{H s}\right)$ and of Foreign traded goods $\left(\mathcal{I}_{F s}\right)$ :

$$
\mathcal{I}_{T s}=\left[\ell_{I}\left(\frac{\mathcal{I}_{H s}}{\ell_{I}}\right)^{1-\theta_{I T}}+\left(1-\ell_{I}\right)\left(\frac{\mathcal{I}_{F s}}{1-\ell_{I}}\right)^{1-\theta_{I T}}\right]^{\frac{1}{1-\theta_{I T}}}, \quad \ell_{I}=n+\kappa_{I} .
$$

$0<\ell_{C}, \ell_{I}<1$ are, respectively, the weights on the Home traded good in tradedgood inputs into consumption and investment. $n$ is the proportion of the world's population living in the Home country. In this paper, we make the simplifying assumption that the two countries are of equal size $\left(n=\frac{1}{2}\right)$. The parameters $\kappa_{C}$ and $\kappa_{I}\left(0<\kappa_{C}, \kappa_{I}<1-n\right)$ determine the amount of local-good bias in the composition of traded goods inputs into consumption and investment, respectively. (For example, there is no local-good bias when $\kappa_{C}=\kappa_{I}=0$ ). We incorporate the empirically-based assumption that the local-good bias is greater in consumption than in investment.

Traded investment inputs are referred to as 'quality-adjusted', because there are investment-specific productivity $(I S P)$ increases:

$$
\begin{aligned}
& \mathcal{I}_{H s}=Q_{H s}^{\frac{1-\alpha}{\alpha}} I_{H s}, \quad \mathcal{I}_{F s}=Q_{F s}^{\frac{1-\alpha}{\alpha}} I_{F s}, \\
& \mathcal{P}_{H s}=\frac{1}{Q_{H s}^{\frac{1-\alpha}{\alpha}}}, \quad \mathcal{P}_{F s}=\frac{P_{F s}}{Q_{F s}^{\frac{1-\alpha}{\alpha}}},
\end{aligned}
$$

where the $Q_{j s}, j=H, F$ are $I S P$ shocks that can be different. ${ }^{19}$ If a $Q_{j s}$ increases, a given physical unit of output of good $j$ can contribute more to investment good output $\left(J_{s}\right)$ than the same unit did before. $I_{H s}$ and $I_{F s}$ are measured in units of Home and Foreign traded goods, respectively, whereas $\mathcal{I}_{H s}$ and $\mathcal{I}_{F s}$ are measured in performance units. For example, $I_{H s}$ and $I_{F s}$ might be measured in numbers of computers in which case $\mathcal{I}_{H s}$ and $\mathcal{I}_{F s}$ might be measured in terms of computing power. Given that the Home traded good is the numeraire, the price of a unit of $I_{H s}$ is unity. $P_{F s}$ is the price of the Foreign traded good in terms of the Home traded good, and $\mathcal{P}_{H s}$ and $\mathcal{P}_{F s}$ are prices of Home and Foreign performance units in terms of the Home traded good.

\footnotetext{
${ }^{19}$ The qualtity shocks are entered with the exponent $\frac{1-\alpha}{\alpha}$ so that if the $Q_{j s}$ are equal, doubling all of them doubles steady-state outputs. More precisely, if $Q_{j s}=Q_{s}, j=H, F, N$, then $\frac{Y_{i s}}{Q_{s}}, i=T, N$ is constant in the nonstochastic steady state. In this paper we assume that $Q_{N s}$ remains constant at unity.
} 
Our ISP shocks are designed to generate effects similar to those of an increase in multifactor productivity in a separate $I C T$ sector. The traded-goods sector can be thought of as being divided into two sub-sectors - one producing investment inputs that are subject to quality improvements and the other producing consumption inputs that are not - with perfect mobility of capital and labor between the two subsectors. Note that all of the $I S P$ shocks affect output of the investment good, which can be used to increase the capital stock in both the traded and nontraded goods sectors.

$Q$ shocks are reflected in the relative prices of investment goods. Using the model results for sectoral prices and quantities, we can construct aggregate prices and quantities. In order to generate model results that are comparable to the data, we construct chain-weighted aggregates. For example, for the relative price of investment, we use the ratio of Fisher indices for the investment $\left(J_{s}\right)$ deflator and the GDP deflator, where the deflator for $J_{s}$ is calculated using the prices of $\mathcal{I}_{H s}, \mathcal{I}_{F s}$, and $I_{N s}$ and the deflator for GDP is calculated using the prices of $C_{H s}, C_{H s}^{*}, C_{N s}, \mathcal{I}_{H s}, \mathcal{I}_{H s}^{*}$, and $I_{N s}$

\subsection{The Budget Constraint}

The agent must also take into account a budget constraint. Income from production of traded and nontraded goods plus interest from claims on Foreign last period must be at least enough to cover purchases of both traded goods and the home nontraded good for use in assembling consumption and investment plus claims on Foreign this period and "portfolio management costs" associated with claims on or liabilities to Foreign: ${ }^{20}$

$$
\begin{gathered}
F\left(\underline{K}_{T s}, \underline{L}_{T s}\right) X_{T s}^{1-\alpha}+F\left(\underline{K}_{N s}, \underline{L}_{N s}\right) X_{N s}^{1-\alpha}+R_{s-1} B_{s-1} \geq \\
{\left[C_{H s}+P_{F s} C_{F s}+P_{N s} C_{N s}+\frac{\mathcal{I}_{H s}}{Q_{H s}^{\frac{1-\alpha}{\alpha}}}+\frac{P_{F s} \mathcal{I}_{F s}}{Q_{F s}^{\frac{1-\alpha}{\alpha}}}+P_{N s} I_{N s}+B_{s}+\frac{\zeta}{2} \frac{B_{s}^{2}}{Z_{T s}}\right] .}
\end{gathered}
$$

$P_{N s}$ is the price of Home nontraded goods in term of Home traded goods. $R_{s}$ is the gross return on bonds denominated in the Home traded good. A positive value of $B_{s}$ indicates claims of Home on Foreign.

\subsection{Relative Prices}

In this paper, we focus on four relative prices. Two of them are the relative prices of the two countries' nontraded goods in terms of their traded goods represented by $P_{N s}$ and $P_{N s}^{*}$, respectively. An asterisk on a variable indicates that it relates to Foreign. The terms of trade (TOT) and real exchange rate $(R E R)$ are given by

$$
T_{O T}=\frac{1}{P_{F s}}, \quad R E R_{s}=\frac{P_{C s}}{P_{F s} P_{C s}^{*}},
$$

\footnotetext{
${ }^{20}$ Portfolio management costs are included to insure that the model has a well-defined steady state. Including these costs is the easiest among several roughly equivalent ways of guaranteeing stationarity as explained by Schmitt-Grohe and Uribe (2003).
} 
where $P_{C s}^{*}$ is the price of the Foreign consumption bundle in terms of the Foreign traded good. The TOT is defined as the number of Foreign traded goods it takes to buy a unit of Home traded goods, so an increase is an improvement. The $R E R$ is the CPI-adjusted exchange rate defined as the number of Foreign consumption bundles it takes to buy a Home consumption bundle, so an increase is an appreciation of the Home currency in real terms. Improvements in the TOT and increases in $P_{N s}$ cause the Home currency to appreciate in real terms but increases in $P_{N s}^{*}$ cause it to depreciate. In the neighborhood of the steady state

$$
\widehat{R E R}_{s}=\nu\left(\widehat{P}_{N s}-\widehat{P}_{N s}^{*}\right)+(1-\nu)\left(\kappa_{C}+\kappa_{C}^{*}\right) \widehat{T O T}_{s}
$$

where a hat over a variable indicates a percentage deviation from its steady-state value. $0<\kappa_{C}^{*}<n$ is the degree of local-good bias in consumption in Foreign, and we assume $\kappa_{C}^{*}=\kappa_{C}$.

\section{Simulations}

In this section we report the results of our simulations. To fix ideas, we first discuss symmetric increases in the levels of $I S P$ in Home and Foreign. Then, we analyze two types of persistent productivity growth shocks suggested by the data: symmetric increases in ISP growth and (perfectly) asymmetric changes in MFP growth. The values of the parameters used in the simulations are in Table A1 in the Appendix. Unless stated otherwise, we assume that Home and Foreign parameters are identical.

In explaining our simulations, we use the terms 'wealth effect' and 'investment incentive'. For us, a shock has a positive wealth effect if it gives rise to an increase in the excess of income over the spending needed to support the initial steady-state path (both measured in Home traded goods). In calculating this excess, we hold constant relative prices of physical units, consumption allocations, effective investment input allocations $\left(\mathcal{I}_{H s}\right.$ and $\left.\mathcal{I}_{F s}\right)$, and bond holdings. ${ }^{21}$ With $M F P$ shocks, income goes up. Agents receive the value of production of traded and nontraded goods through either wages or capital income, and $M F P$ shocks increase the amounts produced. With $I S P$ shocks, spending goes down. There is a fall in the relative price of effective traded-good investment inputs. When there are positive wealth effects, agents can consume more, increase the capital stock by more, or work less. What they choose to do depends on the incentives they face.

A positive investment incentive can arise either because of a fall in the consumption price of (quality-adjusted) investment or because of a rise in the marginal product of capital. ${ }^{22}$ Changes in the consumption price of investment are associated with

\footnotetext{
${ }^{21}$ Since the initial excess is zero, the wealth effect is given by the first line of equation (10) minus the second where $X_{T s}, X_{N s}, Q_{H s}^{\frac{1-\alpha}{\alpha}}$, and $Q_{F s}^{\frac{1-\alpha}{\alpha}}$ are at their post shock values and all other variables are at their initial steady state values. Our definition of the term 'wealth effect' is quite different from the one in Baxter (1995).

${ }^{22}$ For further discussion of the investment incentive see the Appendix.
} 
changes in the GDP price of investment in the same direction. We use the latter variable and call it simply the 'relative price of investment'. U.S. data for this relative price are in F1.1.

\subsection{Symmetric $I S P$ Level Increases}

In our first experiment, there are symmetric permanent increases in the levels of $I S P$. We compare results for two cases: (1) the identical (adjustment) costs case in which adjusting capital-labor $(K-L)$ ratios is costless in both countries $\left(\psi_{K L}=0\right)$, and (2) the higher Foreign (adjustment) costs case in which adjusting $K-L$ ratios is very costly in Foreign $\left(\psi_{K L}^{*}=5000\right)$. In both cases, there are positive costs of adjusting capital stocks that are the same in both countries.

In $\mathrm{F} 2 \mathrm{~A}$ and $\mathrm{F} 2 \mathrm{~B}$, we show the effects of $1 \%$ increases in the productivities of Home and Foreign traded goods that are used as inputs in the assembly of investment goods $\left(Q_{H s}\right.$ and $Q_{F s}$, respectively). Since these increases in the ISP of tradable investment inputs are symmetric, they have the same positive wealth effects in both countries in both cases. In each country, it takes fewer resources to support the initial steady-state path.

We use the case with identical costs (dashed lines) as a benchmark. In this case, the two countries are completely symmetric, so all the effects are the same in the two countries. These results are similar to those for a closed economy in many respects.

It comes as no surprise that the shocks create positive investment incentives. Before adjustment of consumption and investment, there are decreases in the relative prices of investment. With optimal adjustment, the relative prices of investment (F2A.1) fall by roughly $0.45 \%$. The magnitudes of these declines reflect the fact that tradables account for roughly half of investment inputs. After their initial drop, the relative prices of investment remain roughly constant.

In our calibration, the costs of adjusting capital stocks are low enough that (gross) investment shares (F2A.3) increase because quantity increases outweigh price declines. The increases in investment shares by 0.09 pp must be matched by equal decreases in consumption shares (F2A.4). The investment incentive is large enough relative to the wealth effect that there are decreases not only in the shares of consumption but also in the chain-weighted levels (F2B.1). Although the shares of consumption remain below baseline for twenty five years, the levels rise above baseline after four years. The hump-shaped responses of consumption shares are due to the effects of habit in consumption. In each country, there are the same spikes in the excess of (quality-adjusted) investment growth over GDP growth (F2A.2), labor productivity growth (F2A.5), and GDP growth (F2A.7) as well as persistent increases in capital deepening (F2A.6) and hours worked (F2A.8).

Now we turn to the case with higher Foreign costs (solid and dotted lines). Once again, there are positive investment incentives in both countries. Before adjustment of consumption and investment, the declines in the relative prices of investment are the same. However, the positive investment incentive is larger in Home. The marginal product of capital is higher there because there are no $K-L$ adjustment costs. The initial increase in the Home investment share is about twice as great as in the 
identical-costs case. About one third of this change is financed by an additional reduction in the Home consumption share and the remaining two thirds by borrowing from Foreign. As in the identical-costs case, the investment incentive effect is large enough relative to the wealth effects that there are reductions not only in the share of Home consumption but also in its the level. There is a major deterrent to increasing investment further by borrowing more. Nontraded goods constitute a large share of Home investment-assembly inputs and are complements to the other inputs, so either the fall in consumption or the rise in work effort would have to be relatively large. ${ }^{23}$

In contrast, in Foreign the investment incentive is small enough relative to the wealth effect that the investment share is reduced rather than increased. Given that investment inputs are now much cheaper, Foreign residents can maintain their capital stocks and even increase them a little, even though they drastically reduce their investment share. They choose to devote the lion's share of the freed resources to increasing their consumption share because there is a relatively small increase in the incentive to lend to Home.

In Home, there is some magnification of the effects on the excess of investment growth over GDP growth, labor productivity growth, GDP growth, capital deepening, and hours worked. ${ }^{24}$ However, in Foreign, there are significant effects on only three of these variables: GDP growth, labor productivity growth, and hours. The initial spike in labor productivity growth is larger in Foreign (0.14 pp) than in Home (0.1 pp). Output growth increases somewhat less in Foreign, but hours remain virtually unchanged there while they increase significantly in Home. At first, hours in Foreign remain virtually unchanged because of the large cost of changing the capitallabor ratio. Over time, total hours increase as a gradual increase in nontraded hours (not shown) offsets an even more gradual decrease in traded hours (not shown). Two observations help in understanding why: (1) steady-state capital stocks increase in Foreign as much as they do in Home and (2) nontraded investment inputs are complements to traded inputs but do not benefit from an improvement in ISP.

Home runs a trade balance deficit (F2B.3) for about 5 years and a trade surplus for many years thereafter. The higher level of investment in Home increases demand for both tradable investment inputs. The increase in the trade deficit as a share of GDP is at its maximum (-.05 pp) initially when it is about a fourth of the total increase in the Home investment share.

The Home TOT (F2B.4) remains roughly unchanged initially and then deteriorates slowly over time. At first, the supply of and demand for traded goods (not shown) are cut back by roughly equal amounts in Home and in Foreign. In Home, a

\footnotetext{
${ }^{23}$ We find it natural to assume that nontraded goods are complements in the assembly of investment (and consumption) goods. In our simulations the elasticity of substitution between nontraded and traded goods is one-half. Raising it to one has very small quantitative effects. Raising it to four (the value of the elasticity of substitution between the two traded goods) has large effects at the sectoral level and significant but considerably smaller effects at the aggregate level. It is more attractive to use traded goods in both investment and consumption, so investment can be higher without having consumption be any lower. At its peak the trade deficit is $0.10 \mathrm{pp}$ instead of 0.07 pp.

${ }^{24}$ Note that the initial decrease in capital deepening occurs because hours can increase in the period of the shock, but the capital stock cannot.
} 
significant amount of labor (not shown) is shifted from the traded to the nontraded sector. However, almost immediately the supply of traded goods begins to increase faster in Home because the Home traded-good capital stock increases much more rapidly and because Home traded-good hours rebound rapidly. In each country, the relative price of the nontraded goods (F2B.6), $P_{N}$ or $P_{N}^{*}$, rises by roughly the same amount initially. It continues to rise in Foreign but begins to fall in Home because of the divergent movements in consumption assembly, which is relatively intensive in nontraded goods. Initially, the Home currency appreciates in real terms (F2B.5), and equation (12) helps in understanding why. The $R E R$ rises a little initially because the TOT improves, and the movements in the relative prices of nontraded goods offset each other. However, it begins to fall almost immediately because the effects of the divergent movements in the relative prices of nontraded goods reinforce those of the deterioration in the TOT.

\subsection{Symmetric $I S P$ Growth Rate Increases}

The data indicate that there was a persistent increase in $M F P$ growth in the $I C T$ sector in the last half of the 1990s in both the U.S. and Europe. For this reason, it is interesting to analyze persistent symmetric increases in the growth rates of ISP. For simplicity, we restrict our attention to the more relevant case of asymmetric adjustment costs. Like other analysts of persistent growth-rate shocks, we find it necessary to assume that agents must learn the process governing the growth rate shocks in order to obtain results that bear some resemblance to the data. ${ }^{25} \mathrm{We}$ focus on the learning case and show results for the full-information case primarily for purposes of exposition.

We assume that the Home $I S P$ growth rate follows an $A R(1)$ process:

$$
\tilde{Q}_{H s}=0.95 \tilde{Q}_{H s-1}+\varepsilon_{H s},
$$

where a tilde over a variable indicates a growth rate. We set the coefficient on the lagged growth rate equal to 0.95 so that the relative price of investment (F3a.1) decreases by one percent per year during the first six years of the simulation (19962001). This rate of decrease closely matches the one in the U.S. data. The process for the Foreign ISP growth rate is analogous.

In the case with learning, agents hypothesize that $\tilde{Q}_{H s}$ is the sum of a persistent shock $\left(S_{P s}\right)$ and a temporary shock $\left(S_{T s}\right)$ and that it evolves according to

$$
\tilde{Q}_{H s}=S_{P s}+S_{T s}, \quad S_{P s}=0.95 S_{P s-1}+e_{P s}, \quad S_{T s}=e_{T s},
$$

where $e_{P s}$ and $e_{T s}$ are normally distributed innovations. Having observed $\tilde{Q}_{H s}$, the agent infers $S_{P s}$ and $S_{T s}$ using a Kalman filter. We assume that agents set the autoregressive coefficient for their hypothesized persistent process equal to the true

${ }^{25}$ Learning has been used in the analysis of productivity shocks by Erceg, Guerrieri, and Gust (2002) and Edge, Laubach, and Williams (2004). 
coefficient. ${ }^{26}$ The ratio of the variances of $e_{P s}$ and $e_{T s}$ perceived by agents determines how long it takes them to learn. We choose this ratio so that the part of the observed shock attributed to the persistent component is $75 \%$ after five years and virtually $100 \%$ after ten years. The learning process for the Foreign $I S P$ growth rate is analogous.

We choose the $I S P$ growth rate innovations $\left(\varepsilon_{H s}\right.$ for Home) so that they raise the level of $I S P$ by $1 \%$ in the first period. That is, the first-period effects of the $I S P$ growth rate shocks on the levels of $I S P$ are the same as those of the $I S P$ level shock considered in subsection 4.1. Scaling the shocks in this way makes it easy to compare the initial effects in the learning and full information cases. However, it has the implication that the effects of persistent growth rate shocks are an order of magnitude larger because the $I S P$ shocks asymptotically approach levels that are $13 \%$ higher than their preshock levels.

Just as in the case of increases in the levels of $I S P$, the wealth effects are the same in both countries because the shocks are symmetric. However, the wealth effects are smaller in the benchmark case with learning than with full information because agents are not sure that the shock is truly a persistent growth rate shock.

There are positive investment incentives in both countries, but the incentive in Home is greater. The initial decreases in the relative prices of investment are the same in both countries, but the marginal product of capital is higher in Home because there are no $K-L$ adjustment costs. With optimal adjustment, the paths for the relative prices of investment (F3A.1) in Home and Foreign are slightly different because investment demand increases by more in Home, limiting the price decline to some extent. The increase in Home investment demand is reflected both in the increase in the investment share (F3A.3) over time and in the rise in the excess of investment growth over output growth (F3A.2) by about $0.5 \mathrm{pp}$ for the first 5 years. As in the level shocks case, investment is attractive enough that there are decreases in both the share (F3A.4) and the level (F3B.1) of consumption. Also, Home is induced to borrow from Foreign. In contrast, Foreign residents reduce the share of investment but increase the level of investment very gradually because of the high costs of adjusting $K-L$ ratios. They increase the consumption share by somewhat less than they decrease the investment share, and lend to Home.

In order to better understand the adjustment process in the learning case, it is useful to consider the full information case. We show only the results for Home. With full information, the wealth effect is greater. Agents know full well that the relative price of investment will be much lower in the future. For Home residents, investment is unattractive enough initially that they cut the investment share (F3A.3) by roughly $2 \mathrm{pp}$ and the level of investment (F3B.2) by roughly 8\%. The growth rate of investment is temporarily below that of output (F3A.2). A little more than half of the decrease in the investment share is used to raise the consumption share, and the rest is lent to Foreign. We do not discuss the full information case any further, except to note that in the early periods the paths for all the variables depart from

\footnotetext{
${ }^{26}$ If agents must also learn the coefficient of the autoregressive process, they figure out the true shock process much more slowly.
} 
those in the learning case in the manner implied by a larger perceived wealth effect.

With learning, the response of the Home investment share in the first period is a weighted average of what the response would be for a persistent growth shock with full information (-1.77 pp from F3A.2) and what it would be with a level shock $(0.17$ pp from F2A.2). Agents initially attribute only $6 \%$ of the observed movement in $I S P$ to the persistent component and the other $94 \%$ to a level shock. When these percentages are used to weight the effects of the two possible kinds of shocks, the average effect is $0.05 \mathrm{pp}$ (F3A.3). Since the U.S. investment share did not fall in the data when the rate of decline in the relative price of investment became larger, the results with learning seem more plausible to us than those with full information.

Home labor productivity growth (F3A.5) increases on impact by $0.14 \mathrm{pp}$, roughly the amount of the initial increase in $I S P$ times the share in GDP of traded investment inputs (Home and Foreign). As the large increase in investment raises the contribution of capital deepening (F4A.6), labor productivity growth rises above its initial level. In contrast, in Foreign there is essentially no contribution of capital deepening, so the evolution of labor productivity growth closely matches that of the ISP shock.

In Home, hours (F4A.8) rise relatively rapidly and then fall back toward their initial level. In Foreign, hours increase more slowly and reach a higher level.

The Home trade balance (F3B.3) is in deficit for a time but then moves into surplus. The Home TOT (F3B.4) deteriorate over time, making Home traded goods relatively more attractive. The relative price of the nontraded good rises in Foreign because consumption is intensive in nontraded goods. This rise reinforces the deterioration in the Home TOT both of which cause the Home currency to depreciate in real terms (F3B.4).

\subsection{Asymmetric $M F P$ Growth Rate Shocks}

According to the data we report above, in the late 90s the U.S. experienced an increase in the rate of growth of $M F P$ in the non- $I C T$ sector, and taken together European countries experienced a reduction. In both regions, there were changes in several sectors, some of which clearly produce nontraded goods. We perform simulations designed to isolate the effects of persistent changes in MFP growth rates.

For clarity, we make two simplifying assumptions. First, we assume that the shocks are (perfectly) asymmetric by which we mean that the increase in Home and the decrease in Foreign are equal in absolute value. Second, we assume that there are no costs of adjusting $K-L$ ratios in either Home or Foreign. ${ }^{27}$ We report responses only for Home since with symmetric economic structures and asymmetric shocks, Foreign responses are the exact opposites of Home responses.

As a benchmark, we take the case in which there are $M F P$ shocks of equal magnitude in the traded and nontraded sectors as suggested by the data. For comparison, we also consider the more familiar case in which there are $M F P$ shocks only in the traded goods sector. This is the case used in discussions of the well-known

\footnotetext{
${ }^{27}$ Allowing for costs of adjusting $K-L$ ratios in Foreign would make less difference in the case of MFP growth shocks since capital deepening makes a smaller contribution to labor productivity growth in this case.
} 
Harrod-Balassa-Samuelson effect. In both cases, we assume that agents face a learning problem with the same structure as the one described in Subsection 4.2. We also discuss some of the differences between the results for $M F P$ shocks and those for ISP shocks.

In the benchmark case the $M F P$ growth rate increases initially by $0.33 \mathrm{pp}$ in both the traded and nontraded sectors in Home (and declines by $0.33 \mathrm{pp}$ in Foreign). ${ }^{28}$ We have picked the size of the shocks so that the initial rise in Home labor productivity growth matches the one in the simulation for a $1 \%$ ISP growth shock. $^{29}$

There is a positive wealth effect since the outputs of both traded and nontraded goods increase. Before quantities adjust, there is no change in the relative price of investment goods because $M F P$ rises by the same proportion in the traded and nontraded sectors. Nonetheless, there is still a positive investment incentive in Home because the marginal products of capital rise in both sectors.

The positive investment incentive leads to increases in the Home investment share (F4A.3) and in the excess of investment growth over GDP growth (F4A.2). At the point at which it is the largest $(0.8 \mathrm{pp})$, about half of the increase in the investment share is financed by a reduction in the consumption share (F4A.4), and the remainder is financed by borrowing from Foreign. Although the consumption share falls, the wealth effect is strong enough relative to the investment incentive that the level of consumption rises steadily.

In the benchmark $M F P$ case, the initial rise in Home labor productivity growth (F4B.1, solid line) of roughly 0.2 pp reflects both the $0.33 \mathrm{pp}$ increase in $M F P$ growth across the economy and labor's share of income (0.7 pp). As MFP growth subsides, labor productivity growth declines, and the contribution of capital deepening (F4A.6) - as opposed to the shock itself - accounts for a larger and larger share of labor productivity growth.

For the first several years, Home continues to borrow and run a trade-balance deficit (F4B.3). Since Home and Foreign traded goods are good substitutes, the deterioration is substantial, as much as $0.5 \%$ of GDP in our baseline case. Since there is local-good bias in both consumption and investment, the big initial increase in home absorption results in a slight improvement in the terms of trade. However, as Home production continues to expand, the Home terms of trade (F4B.4) deteriorate.

Now we turn to the more familiar case in which the $M F P$ shock is concentrated in the traded sector. We call this case the 'traded-sector-only' case and double the magnitude of the shock since it affects only one sector. The traded-sector-only case is similar to the benchmark case in several ways. In Home there are a positive wealth effect and a positive investment incentive because the output of traded goods and the marginal product of capital in the traded goods sector both rise.

However, there are some differences between the two cases. In the traded-sectoronly case, the path for the relative price of investment (F4A.1) is lower everywhere. The reason is that investment assembly is more intensive in traded goods than con-

\footnotetext{
${ }^{28}$ As before, the $A R(1)$ process governing the evolution of $M F P$ growth has a coefficient of 0.95 .

${ }^{29}$ It is not surprising that with $M F P$ shocks of the type we consider, we cannot match the entire path of labor productivity growth.
} 
sumption assembly. ${ }^{30}$ As a result, the investment share of GDP goes up by more. Since the reduction in the consumption share (F4A.4) is about the same in both cases, the higher investment share is reflected in more borrowing from Foreign accompanied by more deterioration in the trade balance (F4B.3).

The most significant differences from the benchmark case lie in the results for some relative prices. The deterioration of the Home TOT (F4B.4) in the first few years is not very different from that in the benchmark case. In sharp contrast, the relative price of the nontraded good (F4B.6) increases rapidly in Home (and falls rapidly in Foreign) instead of remaining constant and is about $7 \%$ higher in the long run. The large and divergent movements in the relative prices of nontraded goods dominate movements in the TOT, so the $R E R$ (F4B.5) rises in accordance with equation (12). That is, in contrast to the benchmark case, the Home currency appreciates dramatically in real terms, exemplifying the familiar Harrod-BalassaSamuelson effect.

A comparison of the effects of growth rate shocks for $M F P$ with those of $I S P$ reveals some important differences. The $M F P$ and $I S P$ shocks we have chosen are the ones suggested by our reading of the data, not those best suited for a head- tohead comparison of the two kinds of shocks. Nonetheless, our simulations reveal some salient differences between them.

The relative importances of the wealth effect and the investment incentive are opposite in the two cases. With MFP shocks, the relative strength of the wealth effect is great enough that the level of consumption rises from the outset. In contrast, with $I S P$ shocks, the wealth effect is relatively weak, so the level of consumption falls for some time.

The increase in labor productivity can be divided into the contribution of capital deepening and the contribution of the shocks themselves. ${ }^{31}$ Capital deepening is relatively less important with $M F P$ shocks; that is, it accounts for a smaller fraction of labor productivity growth. For instance, in year 2000 (4 years after the start of the simulation) capital deepening accounts for one fourth of labor productivity growth with MFP shocks (F4A.5 and F4A.6) as opposed to one half with ISP shocks (F3A.5 and F3A.6).

As stated above, we calibrate the shocks so that the initial change in labor productivity growth is the same for $M F P$ and for $I S P$ shocks. Given this normalization and our calibration of the parameters, for example, the trade balance deteriorates more with the MFP shocks.

\section{Conclusions}

Our analysis highlights the major difference between positive ISP and MFP shocks. Both shocks lead to marked increases in labor productivity growth. However, with $I S P$ shocks, raising labor productivity growth requires much more investment. In-

\footnotetext{
${ }^{30}$ In our calibration, the traded shares for investment and consumption are 0.48 and 0.37 , respectively.

${ }^{31}$ See the Appendix.
} 
creases in labor productivity are accounted for more by increases in capital deepening than by the shock itself. This finding supports the view that ISP shocks played a relatively more important role than $M F P$ shocks in generating the persistent excess of investment growth over GDP growth in the U.S. in the late 1990s.

Lags in recognition are key in explaining our results for persistent growth shocks. Under full information, with positive $I S P$ shocks investment falls initially and remains below its initial level for a few years. Agents postpone investment because they realize that the price of investment goods will be even lower in the future. With learning, our simulation results are closer to the observed outcomes: investment remains constant initially but rises immediately thereafter.

We confirm that the treatment of nontraded goods can make a big difference. ${ }^{32}$ In the case of $I S P$ shocks, changing the degree of substitutability between traded and nontraded goods has large effects at the sectoral level. In the case of $M F P$ shocks, we can reproduce the conventional Harrod-Balassa-Samuelson result: when a country experiences a positive shock that affects only traded goods, its currency appreciates in real terms and its trade balance deteriorates, changes like those that occurred in the U.S. in the late 1990s. However, the data suggest that real-life MFP shocks also affected nontraded goods. Our model implies that such shocks should have virtually no effect on the $R E R$ and that they should generate a smaller trade balance deterioration.

Our simulations provide some insights regarding the effects of observed productivity shocks. However, it is not surprising that they leave some features of the data unaccounted for. We use a two-country model. But it seems clear that a model with more regions, almost certainly including a separate East Asia bloc, is required to analyze some of the developments of the 1990s, such as the big increase in the U.S. trade account deficit - accompanied by little increase in the bilateral trade surplus of Europe with the U.S. - and the large real appreciation of the dollar. We consider only productivity shocks. But other important shocks influenced economic outcomes in the 1990s. A prime example is the Asian crisis.

\footnotetext{
${ }^{32}$ Like many others, we assume that the dividing line between traded and nontraded goods is exogenous. There is a clear need for more research on endogenous tradability. An early contribution is Dornbusch, Fischer, and Samuelson (1977), and recent contributions include Bergin and Glick (2003) and Ghironi and Melitz (2004). The outsourcing abroad of record keeping and customer service functions is a familiar concrete example.
} 


\section{Appendix}

\section{Lagrangian Expression for Home Agent}

The Lagrangian expression for the home agent is

$$
\begin{gathered}
\sum_{s=t}^{\infty} \beta^{s-t}\left\{\frac{\left[V\left(C_{s}, \mathcal{C}_{s-1}, L_{s}\right)\right]^{1-\gamma}-1}{1-\gamma}+\Lambda_{T s}\left[K\left(J_{T s-1}, K_{T s-1}\right)-K_{T s}\right]\right. \\
+\Lambda_{N s}\left[K\left(J_{N s-1}, K_{N s-1}\right)-K_{N s}\right]+\Lambda_{J s}\left[J\left(Q_{H s}^{\frac{1-\alpha}{\alpha}} \mathcal{I}_{H s}, Q_{F s}^{\frac{1-\alpha}{\alpha}} \mathcal{I}_{F s}, I_{N s}\right)-J_{T s}-J_{N s}\right] \\
+\Lambda_{C s}\left[R_{s-1} B_{s-1}+F\left(\underline{K}_{T s}, \underline{L}_{T s}\right) X_{T s}^{1-\alpha}+P_{N s} F\left(\underline{K}_{N s}, \underline{L}_{N s}\right) X_{N s}^{1-\alpha}-\frac{\zeta}{2} \frac{B_{s}^{2}}{Z_{T s}}\right. \\
\left.-C_{H s}-P_{F s} C_{F s}-P_{N s} C_{N s}-\frac{\mathcal{I}_{H s}}{Q_{H s}^{\frac{1-\alpha}{\alpha}}}-\frac{P_{F s} \mathcal{I}_{F s}}{Q_{F s}^{\frac{1-\alpha}{\alpha}}}-P_{N s} I_{N s}-B_{s}\right]
\end{gathered}
$$

where $\Lambda_{T s}, \Lambda_{N s}, \Lambda_{J s}$, and $\Lambda_{C s}$ are the shadow prices of $K_{T s}, K_{N s}, J=J_{T s}+J_{N s}$, and income.

\section{Parameter Values}

The parameter values used in the simulations are given in Table A1. In the initial steady state $P_{F}, P_{N}, P_{N}^{*}, Q_{T}, Q_{T}^{*}, X_{T}, X_{N}, X_{T}^{*}$, and $X_{N}^{*}$ are all unity.

\section{Table A1: Parameter Values}

\begin{tabular}{|lll|}
\hline$\beta$ & discount factor & 0.98 \\
$\gamma$ & elasticity of marginal utility w.r.t. $V$ & 1.0 \\
$\alpha$ & share of capital in production & 0.35 \\
$\delta$ & depreciation rate & 0.025 \\
$\phi$ & governs capital adjustment costs & 0.2 \\
$\nu_{C} \& \nu_{I}$ & share of nontraded goods in $C \& I$ & $0.63 \& 0.52$ \\
$1 / \theta_{C N}$ & elasticity of substitution - $T \& N$ goods in $C$ & 0.5 \\
$1 / \theta_{I N}$ & elasticity of substitution - $T \& N$ goods in $J$ & 0.5 \\
$n$ & relative size of home country & 0.5 \\
$\kappa_{C}$ & local-good bias in $C_{T}$ & 0.32 \\
$\kappa_{I}$ & local-good bias in $I_{T}$ & 0.08 \\
$1 / \theta_{C T}$ & elasticity of substitution - $H \& F$ goods in $C_{T}$ & 4.0 \\
$1 / \theta_{I T}$ & elasticity of substitution - $H \& F$ goods in $I_{T}$ & 4.0 \\
$\psi_{K L} \& \psi_{K L}^{*}$ & governs capital-labor ratio adjustment costs & $0 \& 5000$ \\
$\zeta$ & governs portfolio management costs & 0.0001 \\
$2 / \chi$ & Frisch elasticity of labor supply & 0.4 \\
$\chi_{0}$ & set so steady-state share of time worked is 0.33 & 0.719 \\
& & \\
\hline
\end{tabular}




\section{Decomposing Labor Productivity Growth}

In this section, we show that the usual decomposition of labor productivity growth into a contribution from capital deepening and a contribution from a productivity shock is as relevant for $I S P$ shocks as it is for $M F P$ shocks. For simplicity, we focus on a special case in which all goods are traded, but the argument generalizes.

The Törnqvist index for quality-adjusted, chain-weighted output growth, which approximates the Fisher index, is given by

$$
\tilde{Y}_{t}^{C W}=S_{C H t} \tilde{C}_{H t}+S_{C H t}^{*} \tilde{C}_{H t}^{*}+S_{I H t}\left(\tilde{I}_{H t}+\frac{1-\alpha}{\alpha} \tilde{Q}_{H t}\right)+S_{I H t}^{*}\left(\tilde{I}_{H t}^{*}+\frac{1-\alpha}{\alpha} \tilde{Q}_{H t}\right),
$$

where $Y_{t}^{C W}, C_{H t}^{*}$, and $I_{H t}^{*}$ are chain-weighted output, consumption exports, and investment exports, respectively, and, for example $S_{C H t}$ is the average of the shares of the consumption of the Home good in total output in periods $t$ and $t-1 .{ }^{33}$

Quality-adjusted output at constant prices $\left(Y_{t}^{C P}\right)$ and its growth rate $\left(\tilde{Y}_{t}^{C P}\right)$ are

$$
\begin{gathered}
Y_{t}^{C P}=C_{H}+C_{H t}^{*}+Q_{H t}\left(I_{H t}+I_{H t}^{*}\right) \\
\tilde{Y}_{t}^{C P}=S_{C H} \tilde{C}_{H t}+S_{C H}^{*} \tilde{C}_{H t}^{*}+S_{I H}\left(\tilde{I}_{H t}+\frac{1-\alpha}{\alpha} \tilde{Q}_{H t}\right)+S_{I H}^{*}\left(\tilde{I}_{H t}^{*}+\frac{1-\alpha}{\alpha} \tilde{Q}_{H t}\right),
\end{gathered}
$$

where in the initial steady state $Q_{t}=1$, and, for example, $S_{C H t}=S_{C H}$. From equations (15) and (17), it is clear that growth of GDP at constant prices can be viewed as the first-order approximation of the Törnqvist index with no trend growth since $\tilde{C}_{H t}=\tilde{C}_{H t}^{*}=\tilde{I}_{H t}+\frac{1-\alpha}{\alpha} \tilde{Q}_{H t}=\tilde{I}_{H t}^{*}+\frac{1-\alpha}{\alpha} \tilde{Q}_{H t}=0$ in the steady state.

Log-linearizing and combining equation (16) and the technology constraint

$$
C_{H}+C_{H t}^{*}+I_{H t}+I_{H t}^{*}=K_{t}^{\alpha} L_{t}^{1-\alpha} X_{t}^{1-\alpha},
$$

yield the usual decomposition in terms of percent deviations from the steady state:

$$
\hat{Y}_{t}^{C P}-\hat{L}_{t}=\alpha\left(\hat{K}_{t}-\hat{L}_{t}\right)+(1-\alpha) \hat{X}_{H t}+\left(S h_{I H}+S h_{I H^{*}}\right) \frac{1-\alpha}{\alpha} \hat{Q}_{H t} .
$$

From equation (19), it is clear that the $I S P$ shock $\left(\hat{Q}_{t}\right)$ can be interpreted as an $M F P$ shock that affects only the investment-producing sector of the economy.

\section{Defining the Investment Incentive}

For us, a positive investment incentive arises for one of two reasons. The first reason is a decrease in the relative price of investment. Under perfect competition, prices equal marginal costs, so this relative price equals the ratio of marginal costs, $\frac{M C_{I t}}{M C_{C t}}$, where $M C_{I t}$ and $M C_{C t}$ are obtained from the cost minimization problems

$$
\begin{gathered}
\left.\min _{I_{H t}, I_{N t}, I_{F t}} I_{H t}+P_{N t} I_{N t}+P_{F t} I_{F t}+M C_{I t}\left[J\left(Q_{H t} I_{H t}, Q_{F t} I_{F t}, I_{N t},\right)-J_{0}\right)\right], \\
\left.\min _{C_{H t}, C_{N t}, C_{F t}} C_{H t}+P_{N t} C_{N t}+P_{F t} C_{F t}+M C_{C t}\left[C\left(C_{H t}, C_{N t}, C_{F t}\right)-C_{0}\right)\right] .
\end{gathered}
$$

$J(\cdot)$ and $C(\cdot)$ are the CES aggregators (6) and (5), and $J_{0}$ and $C_{0}$ are the pre-shock levels of quality-adjusted investment and consumption. Positive ISP shocks lower the relative price of investment. The second reason is an increase in the marginal product of capital. Positive $M F P$ shocks raise the marginal product of capital.

\footnotetext{
${ }^{33}$ Dumagan (2002) shows the relationship between the Törnqvist index and the Fisher ideal index used in computing chain-weighted GDP by the U.S. Bureau of Economic Analysis.
} 


\section{References}

Backus, D., P. Kehoe, and F. Kydland (1994a) "Dynamics of the Trade Balance and the Terms of Trade: The J Curve?", American Economic Review, 84, 84-103.

Backus, D., P. Kehoe, and F. Kydland (1994b) "Relative Price Movements in Dynamic General Equilibrium Models of International Trade", in F. van der Ploeg (ed.) The Handbook of International Macroeconomics, Blackwell, Oxford.

Baxter, M. (1995) "International Trade and Business Cycles", in G. Grossman and K. Rogoff (eds.) Handbook of International Economics, Volume 3, Elsevier, Amsterdam, 1801-1864.

Baxter, M., and M. J. Crucini (1995) "Business Cycles and the Asset Structure of Foreign Trade", International Economic Review, 36, 821-854.

Bergin, P. R., and R. Glick (2003) "Endogenous Tradability and Macroeconomic Implications", NBER Working Paper 9739, National Bureau of Economic Research.

Bosworth, B. P., and J. E. Triplett (2000) "What's New About the New Economy? IT, Economic Growth, and Productivity", processed, Brookings Institution.

Dornbusch, R., S. Fischer, and P. A. Samuelson (1977) "Comparative Advantage, Trade, and Payments in a Ricardian Model with a Continuum of Goods", American Economic Review, 67, 823-839.

Dumagan, J. C. (2002) "Comparing the Superlative Törnqvist and Fisher Ideal Indexes", Economic Letters, 76, 251-58.

Edge, R. M., T. Laubach, and J. C. Williams (2003) "The Responses of Wages and Prices to Technology Shocks", Finance and Economics Discussion Papers 2003-65, Federal Reserve Board.

Edge, R. M., T. Laubach, and J. C. Williams (2004) "Learning and Shifts in LongRun Productivity Growth", Finance and Economics Discussion Papers 2004-21, Federal Reserve Board.

Erceg, C. J., L. Guerrieri, and C. Gust (2002) "Productivity Growth and the Trade Balance in the 1990s: the Role of Evolving Perceptions", processed, Federal Reserve Board.

Fernald, J. G., and S. Ramnath (2004) "The Acceleration in U.S. Total Factor Productivity After 1995: The Role of Information Technology", Economic Perspectives, $1,52-67$.

GGDC (2004) "60-Industry Database”, Groningen Growth and Development Center, (www.ggdc.net).

Ghironi, F., and M. J. Melitz (2004) "International Trade and Macroeconomic Dynamics with Heterogenous Firms", processed, Harvard. 
Greenwood, J., Z. Hercowitz, and P. Krusell (1997) "Long-Run Implications of Investment-Specific Technological Change", American Economic Review, 87, 342362.

Hunt, B., and A. Rebucci (2003) "The U.S. Dollar and the Trade Deficit: What Accounts for the Late 1990s?", processed, International Monetary Fund.

Inklar, R., M. O’Mahony, K. Robinson, and M. Timmer (2003) "Productivity and Competitiveness in the EU and in the U.S.", in M. O'Mahony and B. van Ark (eds.) EU Productivity and Competitiveness: An Industry Perspective Can Europe Resume the Catching-up Process?, Office for Official Publications of the European Communities, Luxembourg, 73-147 (www.ggdc.net).

Jorgenson, D. W. (2004) "Accounting for Growth in the Information Age", in P. Aghion and S. Durlauf (eds.) Handbook of Economic Growth, North Holland, Amsterdam, forthcoming (http://post.economics.harvard.edu/faculty/jorgenson/ papers/papers.html).

Kollmann, R. (1998) "U.S. Trade Balance Dynamics: the Role of Fiscal Policy and Productivity Shocks and of Financial Market Linkages", Journal of International Money and Finance, 17, 637-669.

Laxton, D., and P. Pesenti (2003) "Monetary Rules for Small, Open, Emerging Economies", Journal of Monetary Economics, 50, 1109-1146.

Oliner, S. D., and D. E. Sichel (2000) "The Resurgence of Growth in the Late 1990s: Is Information Technology the Story?", Journal of Economic Perspectives, 14, $3-22$.

Organization for Economic Co-operation and Development (2004) "STAN Database", (www.oecd.org/sti/stan).

Schmitt-Grohe, S., and M. Uribe (2003) "Closing Small Open Economy Models", Journal of International Economics, 61, 163-185.

Schreyer, P. (2001) Measuring Productivity, OECD.

Stockman, A., and L. Tesar (1995) "Tastes and Technology in a Two-Country Model of the Business Cycle: Explaining International Comovements", American Economic Review, 85, 168-185. 